\title{
Effect of SBF on Aß25-35 Induced- Abnormal Changes of PP-1 and Tau Protein Phosphorylation in N2a Cells
}

\author{
He Ke ${ }^{1}$, Ye Yuanyuan ${ }^{2}$, Fan $\mathbf{Q i}^{2}$, Shang Yazhen ${ }^{1,2^{*}}$ \\ ${ }^{I}$ The fourth Hospital of Shijiazhuang, Hebei 050011, China \\ ${ }^{2}$ Institute of Traditional Chinese Medicine, Chengde Medical University; Key Research Laboratory of Anti- \\ dementia of Traditional Chinese Medicine, Hebei Province; Key Laboratory of Traditional Chinese Medicine \\ Research and Development of Hebei Province, Hebei Chengde 067000, China.
}

*Corresponding Author: Shang Yazhen, The fourth Hospital of Shijiazhuang, Hebei 050011, China. Institute of Traditional Chinese Medicine, Chengde Medical University; Key Research Laboratory of Antidementia of Traditional Chinese Medicine, Hebei Province; Key Laboratory of Traditional Chinese Medicine Research and Development of Hebei Province, Hebei Chengde 067000, China.

Abstract:

Objective: To investigate the effects of Scutellaria barbata flavonoids (SBF) on abnormal changes of N2a cell protein Phosphatase-1 (PP-1) and related Tau protein phosphorylation induced by $\beta$-amyloid25-35 (Aß25-35).

Methods: N2a cells were cultured and randomly divided into 7 groups, including control group, model group, PP-1 inhibitor $O A$ group, AB25-35+OA group and SBF three dose treatment groups. The control group was not treated. AB25-35 of 40 $\mu \mathrm{mol} / \mathrm{L}$ was added to the model group, and work for $12 \mathrm{~h}$. OA with a final concentration of $15 \mathrm{nmol} / \mathrm{L}$ was added to the PP1 inhibitor OA group, and fully act for $12 \mathrm{~h}$. SBF of $1.125 \mathrm{mg} / \mathrm{L}, 2.25 \mathrm{mg} / \mathrm{L}$ and $4.5 \mathrm{mg} / \mathrm{L}$ were added to SBF dose treatment groups respectively, and the inhibitor $O A$ with a final concentration of $15 \mathrm{nmol} / L$ was added at the same time, after acting cells for $12 \mathrm{~h}, \mathrm{~A} \beta 25-35$ with a final concentration of $40 \mu \mathrm{mol} / \mathrm{L}$ was added to continue the action for $12 \mathrm{~h}$. The morphology and state of cells were observed under $100 \times$ microscope. The injury degree and survival rate of N2a cells were measured by Lactic dehydrogenase release and MTT assay. Western blot was used to detect the phosphorylation expression levels of PP-1 and Tau protein at Thr205, Thr231, Ser404 and Ser199 of N2a cells in each group.

Results: After overnight cultured, the cells in the control group were observed to be intact, the cell membrane was transparent and the morphology of the cells was shuttle. In the model group, after the cells were treated with a final concentration of $40 \mu \mathrm{mol} / \mathrm{L}$ A $25-35$ for $12 \mathrm{~h}$, the cell membrane was observed to be incomplete and damaged under the microscope, the cells appeared agglomeration, the cell bulges was not obvious and the growth was slow. After treated with three doses of SBF for 24 hours, the three groups of cells was observed that they had different degrees of improvement under the microscope, the growth rate of the cells was faster and the cell membrane was intact. Compared with the control group, the LDH release of $N 2$ a cells increased by $8 \%$ in the model group $(p<0.01)$, and significantly decreased by $1.82 \%$ in the OA group $(p<0.01)$. Compared with the model group, the LDH release of $N 2$ a cells decreased by $2.64 \%$ in $A \beta 25-35+O A$ group ( $<<0.01)$. Compared with A $325-35+O A$ group, $L D H$ release of $N 2$ a cells decreased by $2.89 \%$ in $S B F 1.125 \mathrm{mg} / \mathrm{mL}$ group ( $p<0.01)$, and decreased by $3.41 \%$ in SBF $2.25 \mathrm{mg} / \mathrm{mL}$ group $(p<0.01)$, and decreased by $4.34 \%$ in SBF $4.5 \mathrm{mg} / \mathrm{mL}$ group $(p<0.01)$. Compared with the control group, the survival rate of $N 2$ a cells decreased by $17.89 \%$ in the model group $(p<0.01)$, and decreased by $16.82 \%$ in the OA group $(p<0.01)$. Compared with the model group, the survival rate of $N 2 a$ cells increased by $23.03 \%$ in AB25-35+OA group $(p<0.01)$. Compared with AB25-35+OA group, the survival rate of $N 2 a$ cells increased by $0.61 \%$ in SBF $1.125 \mathrm{mg} / \mathrm{mL}$ group ( $p<0.01)$, and increased by $12.89 \%$ in $S B F 2.25 \mathrm{mg} / \mathrm{mL}$ group $(p<0.01)$, and increased by $25.90 \%$ in $S B F 4.5 \mathrm{mg} / \mathrm{mL}$ group $(p<0.01)$. Compared with the control group, expect for the decreased protein expression levels of PP-1 and p-Tau (Thr205), the protein expression levels of p-Tau (Ser199), p-Tau (Ser404) and $p$-Tau (Thr231) were increased in the model group. In the OA group, expect for the decreased protein expression levels of PP-1, the phosphorylated Tau protein expression levels at Ser199, Thr205, Ser404 and Thr231 these four sites were increased $(p<0.01)$. Compared with the model group, protein expression levels of PP-1 and p-Tau (Thr231) were decreased, the phosphorylated Tau protein expression levels at Ser199, Thr205 and Ser404 sites were increased. Compared with the AB25-35+OA group, expect for the decreased protein expression levels of p-Tau (Ser404), the protein expression levels of PP-1, p-Tau (Ser199), p-Tau (Thr205) and p-Tau (Thr231) were increased in the SBF low dose treatment group. In the SBF medium dose treatment group, the protein expression levels of PP-1, p-Tau (Thr205) and p-Tau (Thr231) were increased, while the phosphorylated Tau protein expression levels at Ser199 and Ser404 sites were both decreased. In the SBF high dose group, expect for the increased protein expression levels of PP-1, the protein expression levels of p-Tau (Ser 199), $p$ Tau (Thr205), p-Tau (Ser404) and p-Tau (Thr231) were decreased.

Conclusion: SBF can up-regulate the activity of PP-1 to inhibit the hyperphosphorylation of Tau protein expression levels at Thr205, Thr231, Ser404 and Ser199 sites.

Keywords: Scutellaria barbata flavonoids, N2a cells, PP-1, Tau protein phosphorylation 


\section{INTRODUCTION}

Alzheimer disease (AD) is a degenerative disease of the central nervous system that usually occurs in old age. With the aggravation of population aging, the incidence of $\mathrm{AD}$ is increasing year by year. The number of AD patients worldwide was about 46.8 million in 2015 and will reach 114 million by 2050, which will bring increasingly heavy economic and social burden to the world. Therefore, exploring a drug that can effectively treat $\mathrm{AD}$ has become the focus of attention from all walks of life ${ }^{[1]}$. The main clinical manifestations of AD patients were progressive impairment of cognition, memory function and daily living ability. Senile plaques (SP) formed by $\beta$-amyloid protein (A $\beta$ ) deposition and neuro fibrillary tangles (NFT) formed by intracellular hyperphosphorylation of Tau protein are the main pathological features of $\mathrm{AD}^{[2]}$. Because the treatment of $\mathrm{AD}$ is more complex, and traditional Chinese medicine has great therapeutic potential in this respect, our laboratory established Alzheimer's model in vivo and in vitro. It has found that SBF can reduce the phosphorylation level of Tau protein in Alzheimer's disease. It is mainly achieved by regulating the activity of protein phosphokinase, including GSK-3 $\beta$, CDK 5 and PKA. The phosphorylation level of Tau protein is not only affected by some phosphokinases, but also affected by some phosphatases, including protein phosphatase-1 (PP-1), protein phosphatase 2A (PP2A), protein phosphatase 2B (PP2B) and protein phosphatase 2C (PP2C). PP-1 is one of the most widely distributed phosphatases in cells of the body ${ }^{[3]}$. It is involved in signal pathway, gene expression, regulation of cell cycle and memory formation and other physiological functions. Because the degree of clinical dementia of $\mathrm{AD}$ patients is positively correlated with the aggregation degree of hyperphosphorylation Tau protein, and SBF, as the above ground isolated extract of Scutellaria barbata D.Don, has a certain anti-alzheimer's effect. Therefore, in order to further explore whether SBF can reduce the hyperphosphorylation of Tau protein expression level at Thr205, Thr231, Ser404 and Ser199 sites by regulating PP-1 activity. In this study, the AD model of hyperphosphorylation of Tau protein was established to study the regulation function of SBF on the hyperphosphorylation of Tau protein. The purpose of this study was to further research other action mechanism of SBF on $\mathrm{AD}$.

\section{Materials ANd Methods}

\subsection{Experimental Material and Instrument}

Scutellaria barbata flavonoids (SBF) were prepared by the Institute of Traditional Chinese Medicine of Chengde Medical College, and their total flavonoids purity was 93.1\%. N2a cells is mouse brain neuroma cells and provided by Beijing Dingguo Changsheng Biotechnology Co. Ltd., China. High sugar DMEM (Catalog No. 8511010130) was purchased from GENVIEW Company, China. Fetal bovine serum (Catalog No. SF0016500) was supplied by France Scitecher Company. A $\beta_{25-35}$ (Catalog No. A0331A) provided by Dalian Meilun Company, China. PP-1 inhibitor OA (Catalog No. LOT\#SLBQ3290V) was purchased from America. P-Tau (Thr205), p-Tau (Thr231), p-Tau (Ser404) were supplied by American SAB Company. P-Tau (Ser199) was supplied by abcam Company, British. PP-1 primary antibody (Catalog No. bs-3756R) was purchased from Beijing Boaosen Biotechnology Co. Ltd., China. And goat anti-rabbit secondary antibody (Catalog No. GR288027-15) was supplied by abcam Company, British. $\beta$-actin primary antibody (Catalog No. M1210-2) was purchased from Hua'an Biotechnology Co., Ltd., China. $\beta$-actin secondary antibody (Catalog No. AS100) was supplied by American Medicine Mingkangde Company. Other reagents were from ordinary commercial sources.

\subsection{Experimental Methods}

N2a cells were cultured in $90 \%$ high glucose DMEM complete culture medium, which contains $10 \%$ FBS and placed in $37{ }^{\circ} \mathrm{C}$ and $5 \% \mathrm{CO} 2$ incubator to culture. The culture medium was replaced in each day. The cells were performed to passage by the way of enzyme digestion when the cells density reaches the confluence degree of $80 \%-90 \%$. The logarithmic N2A cells were inoculated on the 96-well aseptic plates cell culture plate at the density of $1.5 \times 104$ per $\mathrm{mL}$ per well, and $100 \mu \mathrm{L}$ per well was added to each well, and incubated at $37{ }^{\circ} \mathrm{C}$ and $5 \% \mathrm{CO} 2$ incubator for $12 \mathrm{~h}$. After that, they were randomly divided into 7 groups: control group, model group, OA group, the A $325-35+\mathrm{OA}$ group, the SBF low dose $(1.125 \mathrm{mg} / \mathrm{L})$ treatment group, the SBF medium dose $(2.25 \mathrm{mg} / \mathrm{L})$ treatment group and the SBF high dose $(4.5 \mathrm{mg} / \mathrm{L})$ treatment group. The control group contains 3\% FBS and $97 \%$ high-glucose DMEM. Model group makes A $\beta 25-35$ have a final concentration of $40 \mu \mathrm{mol} / \mathrm{L}$ in $3 \% \mathrm{FBS}$ and A $\beta 25$ 35 culture medium and action $12 \mathrm{~h}$. In the OA group, OA with a final concentration of $15 \mathrm{nmol} / \mathrm{L}$ was 
added into the culture medium which contains 3\% FBS and high glucose phenol red to act $12 \mathrm{~h}$. In the A $325-35+O A$ group, OA with a final concentration of $15 \mathrm{nmol} / \mathrm{L}$ was added into the culture medium which contains $3 \% \mathrm{FBS}$ and high glucose phenol red to act $12 \mathrm{~h}$, then $\mathrm{A} \beta 25-35$ with a final concentration of $40 \mu \mathrm{mol} / \mathrm{L}$ was added to act $12 \mathrm{~h}$. In different concentrations of SBF+A $\beta 25-35+\mathrm{OA}$ group, SBF was dissolve in 3\% FBS and 97\% high glucose phenol red culture medium, so that the final concentration of SBF is respectively $1.125 \mathrm{mg} / \mathrm{L}, 2.25 \mathrm{mg} / \mathrm{L}$ and $4.5 \mathrm{mg} / \mathrm{L}$, at the same time, the OA with a final concentration of $15 \mathrm{nmol} / \mathrm{L}$ was added and action $12 \mathrm{~h}$, then the A $\beta 25-35$ with a final concentration of $40 \mu \mathrm{mol} / \mathrm{L}$ was added to act for $12 \mathrm{~h}$.

\subsection{Microscopic Observation of the Effect of SBF on Morphological Damage of N2A Cells Induced by $\mathbf{A} \boldsymbol{\beta}_{25-35}$}

Before N2a cells were added with various reagents and SBF, the morphology and growth state of N2a cells were observed under $1 \times 100$ times microscope, and the photos of the cells were preserved.

\subsection{Determination of Injury Degree and Survival Rate of N2a Cells}

\subsubsection{Detection of Damage Degree of N2a Cells by Spectrophotometry}

The cell supernatant was added to the corresponding well of 96-well plates. According to the LDH kit, the corresponding amount of reagent is added in turn. And the release of lactic dehydrogenase (LDH) of N2A cells was determined by spectrophotometry.

\subsubsection{Detection of Survival Rate of N2a Cells by MTT Assay}

The cell liquid of the original 96-well plates was discarded and $100 \mu \mathrm{L}$ MTT solution with final concentration of $0.5 \mathrm{mg} / \mathrm{L}$ was added to each well. After incubation, MTT solution was absorbed and $100 \mu \mathrm{L}$ DMSO solution was added in turn. The cell survival rate was measured by ELIASA.

\subsection{Effect of SBF on Thr205, Thr231, Ser404 and Ser199 of Tau Protein Phosphorylation Sites Damaged by Aß25-35 in N2a Cells}

N2a cells were cultured in $90 \%$ high glucose DMEM complete culture medium, which contains $10 \%$ FBS and placed in $37^{\circ} \mathrm{C}$ and $5 \% \mathrm{CO}_{2}$ incubator to culture. The cells were performed to passage by the way of enzyme digestion. The logarithmic N2A cells were inoculated on the T25 aseptic cell culture bottle at the density of $1 \times 10^{5}$ per $\mathrm{mL}$ per bottle, and $7 \mathrm{~mL}$ per bottle, and incubated at $37{ }^{\circ} \mathrm{C}$ and $5 \%$ $\mathrm{CO} 2$ incubator for $12 \mathrm{~h}$. After that, they were randomly divided into 7 groups: control group, model group, PP-1 inhibitor OA group, the $\mathrm{A} \beta_{25-35}+\mathrm{OA}$ group, the $\mathrm{SBF}$ low dose $(1.125 \mathrm{mg} / \mathrm{L})$ treatment group, the SBF medium dose $(2.25 \mathrm{mg} / \mathrm{L})$ treatment group and the SBF high dose $(4.5 \mathrm{mg} / \mathrm{L})$ treatment group. The control group contains 3\% FBS and 97\% high glucose phenol red culture medium. Model group makes $A \beta_{25-35}$ have a final concentration of $40 \mu \mathrm{mol} / \mathrm{L}$ in $3 \%$ FBS and $97 \%$ high glucose phenol red culture medium and action $12 \mathrm{~h}$. In the $A \beta_{25-35}+\mathrm{OA}$ group, OA with a final concentration of $48 \mathrm{nmol} / \mathrm{L}$ was added into the culture medium which contains 3\% FBS and 97\% high glucose phenol red to act 12 $\mathrm{h}$, then $\mathrm{A} \beta_{25-35}$ with a final concentration of $40 \mu \mathrm{mol} / \mathrm{L}$ was added to act $12 \mathrm{~h}$. In three dose treatment groups of SBF, SBF was dissolve in 3\% FBS and 97\% high glucose phenol red culture medium, so that the final concentration of SBF is respectively $1.125 \mathrm{mg} / \mathrm{L}, 2.25 \mathrm{mg} / \mathrm{L}$ and $4.5 \mathrm{mg} / \mathrm{L}$, at the same time, the OA with a final concentration of $15 \mathrm{nmol} / \mathrm{L}$ was added and action $12 \mathrm{~h}$, then the $A \beta_{25-35}$ with a final concentration of $40 \mu \mathrm{mol} / \mathrm{L}$ was added to act for $12 \mathrm{~h}$. Each bottle of cells was slowly transferred into a $10 \mathrm{~mL}$ centrifuge tube, centrifuged and discard the cell supernatant. Then $1.2 \mathrm{~mL}$ PBS was added. They were transferred into a $1.5 \mathrm{~mL}$ centrifuge tube, centrifuged and discard the cell supernatant. Then they were put into the refrigerator at $-80^{\circ} \mathrm{C}$ to save.

\subsubsection{Protein Quantification by BCA}

Cracking liquid $150 \mu \mathrm{L}$ was added into each group of cells, and they were cracking on the ice for 20 min, centrifuged $20 \mathrm{~min}$. After that, the supernatant is protein. The standard protein and BCA work fluid was prepared according to the requirement, and quantitative. The absorbance value at $562 \mathrm{~nm}$ was measured with a ELIASA. And the protein concentration in the sample was calculated. The remaining samples was mixed with $5 \times$ protein loading sample buffer at a ratio of $4: 1$, denatured $5 \mathrm{~min}$ at $100{ }^{\circ} \mathrm{C}$. After that, they were stored in the $-20{ }^{\circ} \mathrm{C}$ refrigerator.

\subsubsection{Western blot method detect the protein expression level}

Western blot was used to detect Tau protein phosphorylation expression levels at Ser199, Ser214, Ser404, Thr231 sites and PP-1 protein expression levels of each group of N2a cells. Separation by $30 \%$ 

Cells

polyacrylamide gel electrophoresis, and then transfer membrane. The PVDF membrane was closed in TBST of 5\% skimmed milk powder for $2 \mathrm{~h}$. The primary antibody concentration, Thr205 (1:500), Thr231 (1:500), Ser404 (1:500), Ser199(1:15000), and PP-1 (1:300), were placed in the $4{ }^{\circ} \mathrm{C}$ refrigerator overnight, then incubated for $5 \mathrm{~h}$ the next day. The second antibody concentration (1:5000), was incubated at room temperature for an hour and a half. Tanon chemiluminescence image analysis system was used for image development, and IBM SPSS Statistics 21 statistical software was used to analyze the strips.

\section{Statistical ANAlysis}

The results of the study were statistically analyzed by IBM SPSS Statistics 21, expressed as means \pm standard deviation (Means \pm SD). Multiple groups of samples means were compared by one-way ANOVA, the pairwise comparison between means was conducted by the method of least significant difference (LSD). The $\mathrm{P}<0.05$ difference was statistically significant.

\section{Results}

\subsection{Effect of SBF on Morphological Damage of N2a Cells Induced by Aß25-35}

As shown in Figure 1, after overnight cultured, the cells in the control group were observed to be intact and were in the shape of a shuttle, the cell membrane was transparent. In the model group, after the cells were treated with a final concentration of $40 \mu \mathrm{mol} / \mathrm{L} \mathrm{A} \beta_{25-35}$ for $12 \mathrm{~h}$, the cell membrane was observed to be incomplete and damaged under the microscope, the cells appeared agglomeration, the cell bulges was not obvious and the growth was slow. After treated with three doses of SBF for 24 hours, the three groups of cells was observed that they had different degrees of improvement under the microscope, the growth rate of the cells was faster and the cell membrane was intact.

\subsection{Effect of SBF on LDH Release and Survival Rate of N2a Cells Induced by Aß25-35}

\subsubsection{Effect of SBF on LDH Release of N2A Cells Induced by $A \beta_{25-35}$}

As shown in Figure 1, compared with the control group, the LDH release of N2a cells increased by $8 \%$ in the model group $(p<0.01)$, and significantly decreased by $1.82 \%$ in the OA group $(p<0.01)$. Compared with the model group, the LDH release of $\mathrm{N} 2 \mathrm{a}$ cells decreased by $2.64 \%$ in $\mathrm{A} \beta_{25-35}+\mathrm{OA}$ group $(\mathrm{p}<0.01)$. Compared with $\mathrm{A} \beta_{25-35}+\mathrm{OA}$ group, LDH release of N2a cells decreased by $2.89 \%$ in SBF $1.125 \mathrm{mg} / \mathrm{mL}$ group ( $<<0.01$ ), and decreased by $3.41 \%$ in $\mathrm{SBF} 2.25 \mathrm{mg} / \mathrm{mL}$ group $(\mathrm{p}<0.01)$, and decreased by $4.34 \%$ in $\mathrm{SBF} 4.5 \mathrm{mg} / \mathrm{mL}$ group $(\mathrm{p}<0.01)$.

\subsubsection{Effect of SBF on Survival Rate of N2a Cells Induced by AB25-35}

As shown in Figure 3, compared with the control group, the survival rate of N2a cells decreased by $17.89 \%$ in the model group $(\mathrm{p}<0.01)$, and decreased by $16.82 \%$ in the OA group $(\mathrm{p}<0.01)$. Compared with the model group, the survival rate of $\mathrm{N} 2 \mathrm{a}$ cells increased by $23.03 \%$ in $\mathrm{A} \beta 25-35+\mathrm{OA}$ group $(\mathrm{p}<0.01)$. Compared with $\mathrm{A} \beta 25-35+\mathrm{OA}$ group, the survival rate of $\mathrm{N} 2 \mathrm{a}$ cells increased by $0.61 \%$ in SBF $1.125 \mathrm{mg} / \mathrm{mL}$ group ( $\mathrm{p}<0.01$ ), and increased by $12.89 \%$ in SBF $2.25 \mathrm{mg} / \mathrm{mL}$ group ( $\mathrm{p}<0.01)$, and increased by $25.90 \%$ in SBF $4.5 \mathrm{mg} / \mathrm{mL}$ group $(\mathrm{p}<0.01)$.

\subsection{Effect of SBF on the Expression Level of PP-1 and Tau Protein at Various Phosphorylation Sites in N2a Cells Induced by A $\mathbf{\beta 2 5 - 3 5}$}

\subsubsection{Effect of SBF on the Expression of PP-1 Abnormal Protein in N2a Cells Induced by AB25-35}

As shown in Figure 4, compared with the control group, the expression level of PP-1 protein in N2a cells decreased by $0.05 \%$ in the model group ( $p>0.05$ ), and the expression level decreased by $21.65 \%$ in the OA group $(\mathrm{p}<0.05)$. Compared with the model group, the protein expression levels decreased by $39.22 \%$ in the $A \beta_{25-35}+\mathrm{OA}$ group ( $\mathrm{p}<0.01$ ). Compared with the $\mathrm{A} \beta_{25-35}+\mathrm{OA}$ group, the expression level of protein increased by 1.95 times in the SBF low dose treatment group $(\mathrm{p}<0.01)$, and increased by $89.11 \%$ in the SBF medium dose treatment group $(\mathrm{p}<0.01)$, and increased by 1.29 times in the SBF high dose treatment group $(\mathrm{p}<0.01)$.

\subsubsection{Effect of SBF on the expression of phosphorylation Tau protein at Thr205 site in N2A cells induced by $A \beta 25-35$}

As shown in Figure 5, compared with the control group, the expression level of PP-1 protein in N2a cells decreased by $2.29 \%$ in the model group ( $p>0.05)$, and the expression level increased by $10.39 \%$ in the OA group $(\mathrm{p}<0.05)$. Compared with the model group, the protein expression levels increased by 
$2.26 \%$ in the $\mathrm{A} \beta 25-35+\mathrm{OA}$ group ( $\mathrm{p}>0.05$ ). Compared with the $\mathrm{A} \beta 25-35+\mathrm{OA}$ group, the expression level of protein increased by $16.14 \%$ in the SBF low dose treatment group ( $>0.05)$, and increased by $6.99 \%$ in the SBF medium dose treatment group ( $>0.05$ ), and decreased by $2.86 \%$ in the SBF high dose treatment group ( $>0.05)$.

\subsubsection{Effect of SBF on the expression of phosphorylation Tau protein at Thr231 site in N2A cells induced by $A \beta 25-35$}

As shown in Figure 6, compared with the control group, the expression level of PP-1 protein in N2a cells increased by $14.23 \%$ in the model group ( $p>0.05)$, and the expression level increased by $11.21 \%$ in the OA group ( $p>0.05)$. Compared with the model group, the protein expression levels decreased by $5.23 \%$ in the $\mathrm{A} \beta 25-35+\mathrm{OA}$ group ( $\mathrm{p}>0.05$ ). Compared with the A $225-35+\mathrm{OA}$ group, the expression level of protein increased by $20.60 \%$ in the SBF low dose treatment group $(p<0.01)$, and increased by $2.43 \%$ in the SBF medium dose treatment group ( $p>0.051$ ), and decreased by $24.26 \%$ in the SBF high dose treatment group $(\mathrm{p}<0.01)$.

\subsection{Effect of SBF on the Expression of Phosphorylation Tau Protein at Ser404 Site in N2a Cells Induced by A $\beta 25-35$}

As shown in Figure 7, compared with the control group, the expression level of PP-1 protein in N2a cells increased by $22.72 \%$ in the model group $(\mathrm{p}<0.05)$, and the expression level increased by $25.10 \%$ in the OA group ( $p>0.05)$. Compared with the model group, the protein expression levels increased by $21.40 \%$ in the $\mathrm{A} \beta 25-35+\mathrm{OA}$ group $(\mathrm{p}<0.05)$. Compared with the $\mathrm{A} \beta 25-35+\mathrm{OA}$ group, the expression level of protein decreased by $6.53 \%$ in the SBF low dose treatment group ( $\mathrm{p}<0.05)$, and decreased by $28.70 \%$ in the SBF medium dose treatment group ( $<<0.01$ ), and decreased by $50.10 \%$ in the SBF high dose treatment group $(\mathrm{p}<0.01)$.

\subsection{Effect of SBF on the Expression of Phosphorylation Tau Protein at Ser199 Site in N2a Cells Induced by A $\beta 25-35$}

As shown in Figure 8, compared with the control group, the expression level of PP-1 protein in N2a cells increased by $13.98 \%$ in the model group ( $p>0.05)$, and the expression level increased by $34.28 \%$ in the OA group $(\mathrm{p}<0.05)$. Compared with the model group, the protein expression levels increased by $13.09 \%$ in the $A \beta 25-35+O A$ group ( $p>0.05$ ). Compared with the $A \beta 25-35+O A$ group, the expression level of protein increased by $25.80 \%$ in the SBF low dose treatment group ( $p>0.05)$, and decreased by $43.51 \%$ in the SBF medium dose treatment group ( $<<0.05$ ), and decreased by $13.24 \%$ in the SBF high dose treatment group ( $>0.05)$.

\section{DISCUSSION}

Tau protein is a member of the microtubule binding protein family, and it is mainly concentrated in the temporal lobe, frontal lobe, hippocampus and neurons in the entorhinal area of the brain ${ }^{[4-5]}$. Tau protein has a wide range of functions. It can help the center of microtubule tissue transport lysosomes and mitochondria and it is involved in the process of oligodendrocytes forming myelin sheath. In addition, Tau protein can stabilize the microtubules of neurons and promote the growth of neurons. The axons of the peripheral nerves contain Tau protein, and its binding ability is significantly higher than that of the cell body and dendrites of neurons, which creates conditions for the growth and extension of axons ${ }^{[6-7]}$. However, the abnormal expression of Tau protein will make it lose its stabilizing effect on microtubules, which will lead to the functional degradation of nerve cells and the corresponding nervous system diseases ${ }^{[8]}$. According to the theory of Tau origin ${ }^{[9]}$, Tau protein is abnormally hyperphosphorylation, and paired helical filaments (PHF) tangles with each other to form flocculation NFT, which eventually leads to neuronal death, then further leads to $\mathrm{AD}$. The theory of $\mathrm{A} \beta$ suggests that the occurrence of $A D$ is due to the imbalance between the production and clearance of $A \beta^{[10]}$. When the production of $A \beta$ is greater than clearance, soluble and non-soluble $\mathrm{A} \beta$ peptide accumulate in the brain, which resulting in neuronal toxicity. Research shows that abnormal phosphorylation of Tau protein at Thr205,Thr231, Ser404 and Ser199 sites in NFT of AD is not only affected by GSK-3 $\beta$, CDK5 and PKA protein phosphokinases, but also affected by protein phosphate kinase PP-1, PP2A, PP2B and PP2 ${ }^{[11]}$. In eukaryotes, the dephosphorylation of serine / threonine residues is mainly accomplished by four protein phosphatases, including PP-1, PP2A, PP2B and PP2C, in which the activities of PP-1 and PP2A account for more than $90 \%$. PP-1 is an important serine / threonine phosphatase in eukaryotic cells, which can remove phosphate from phosphorase $\alpha$ and phosphatase kinase ( $\beta$ subunit), and play an important role 
in regulating cell apoptosis, gene expression, glucose and lipid metabolism and memory formation ${ }^{[12]}$. $\mathrm{OA}$ is one of the known selective inhibitors of PP-1, and relevant studies have confirmed that OA can specifically reduce the activity of PP-1 and cause abnormal hyperphosphorylation of Tau protein, thus resulting in the toxicity of neurons ${ }^{[13]}$. Mouse brain neuroma cells (N2a cells) can gradually transformed into cell lines after continuous differentiation and no longer have the characteristics of tumor cells. Because the cell can produce a large number of microtubulin and act as a contractile system in nerve cells, and it was found in our laboratory that $\mathrm{A} \beta_{25-35}$ has toxic effect on $\mathrm{N} 2 \mathrm{~A}$ cells, and its toxic fragment is one of the main mechanisms of $\mathrm{AD}$, which will lead to the hyperphosphorylation of Tau protein in the brain of $\mathrm{AD}$ patients. Therefore, N2a cells were selected to explore the other pathogenesis of $\mathrm{AD}$ in this study. Previous studies in our laboratory shows that SBF has certain inhibitory effect on the phosphorylation of Tau protein induced by $A \beta_{25-35}$ in N2a cells, and it could inhibit the activity of GSK$3 \beta$, CDK 5 and PKA, so as to reduce the phosphorylation of Tau protein.

LDH is a key enzyme in glycolysis. Up-regulation of LDH can induce glycolysis metabolism of tumor cells under hypoxia conditions. In the cell experiment, the amount of LDH release is an important indicator to detect the cell damage rate. In the preliminary study of N2a cells, it was found that LDH in N2A cells in model group was $8 \%(\mathrm{p}<0.01)$ higher than that in control group, indicating that the damage rate of $\mathrm{N} 2 \mathrm{a}$ cells was increased and the morphology of N2a cells was seriously damaged. Compared with $\mathrm{A} \beta_{25-35}+\mathrm{OA}$ group, $\mathrm{LDH}$ in $\mathrm{N} 2$ a cells of SBF three dose treatment groups decreased by $2.89 \%$, $3.41 \%$ and $4.34 \%$, respectively $(\mathrm{p}<0.01)$, and presented a dose-dependent relationship, indicating that SBF could improve the survival rate of N2a cells and has a better protective effect on cells. MTT assay can be used to detect the survival rate of cells, which is now used in many experimental laboratories for basic drug research. This study found that compared with the control group, the survival rate of N2a cells in the model group was decreased by $17.89 \%(\mathrm{p}<0.01)$. Compared with the $\mathrm{A} \beta_{25-35}+\mathrm{OA}$ group, the survival rate of N2a cells in the SBF three dose treatment groups increased by $0.61 \%, 12.89 \%$ and $25.90 \%$, respectively $(\mathrm{p}<0.01)$, indicating that SBF significantly improved the damage of N2a cells induced by $\mathrm{A} \beta_{25-35}$.

The results of this study showed that the protein expression level of PP-1 in N2a cells of A $\beta$ group was decreased, which indicated that $\mathrm{A} \beta$ can reduce the activity of PP-1 and promote abnormal hyperphosphorylation of Tau protein. After the application of OA, the protein expression level of PP-1 in N2a cells was significantly decreased, indicating that PP-1 activity was decreased, further indicating that OA inhibited the activity of PP-1. The protein expression level of PP-1 in N2A cells was also significantly decreased in $\mathrm{A} \beta_{25-35}+\mathrm{OA}$ group, which indicated that $\mathrm{OA}$ could significantly inhibit the activity of PP-1 in N2A cells induced by $A \beta_{25-35}$, and make Tau protein not dephosphorylated and increase the phosphorylation level. The protein expression level of PP-1 in N2a cells were all increased in the three SBF dose groups, indicating that SBF can significantly increase the protein expression levels of PP-1 in N2a cells induced by $\mathrm{A}_{25-35}$.

The results of the study showed that Tau protein expression levels at Thr231, Ser404 and Ser199 sites were all increased in N2a cells except Thr205 site, indicating that the activity of PP-1 was increased and the hyperphosphorylation of Tau protein was promoted. Tau protein expression levels at Thr205, Thr231, Ser404 and Ser199 sites were also increased in N2a cells of OA group, indicating that the activity of PP-1 was increased and the phosphorylation level of Tau protein was also increased. After OA was added to the model group, the expression of Tau protein increased at Thr205, Thr231 Ser404 and Ser199 sites, which indicated that the activity of PP-1 was significantly increased, further indicating that $\mathrm{OA}$ and $\mathrm{A} \beta_{25-35}$ acting on cells together could increase the activity of PP-1. The stronger the activity of PP-1, the stronger the phosphorylation level of Tau protein. At the sites of Thr205, Thr231 and Ser199, the expression level of Tau protein in SBF low dose treatment group showed an upward trend, indicating that low dose SBF did not decrease the hyperphosphorylation of Tau protein at Thr205, Thr231 and Ser199 sites. Inhibition of PP-1 activity can lead to abnormal activation of CDK5, GSK-3 $\beta$ and PKA, and abnormal increase of phosphorylation level of Tau protein. Activated GSK-3 $\beta$ can inhibit the activity of PP-1 by promoting the phosphorylation of C subunit of PP2A at Tyr307 site, which leads to the excessive increase of phosphorylation level of Tau protein. These results suggest that the application of suitable SBF dose is very important to study the mechanism of AD. The expression level of Tau protein was increased at Thr205 and Thr231 sites in SBF medium dose treatment group, indicating that middle dose SBF did not decrease the hyperphosphorylation level of Tau protein at Thr205 and Thr231 sites, which may be related to the increase of Tau protein phosphorylation level at 
the phosphorylation site Ser199 and Thr205 of PP-2A. The expression level of Tau protein decreased at Thr205, Thr231, Ser404 and Ser199 sites in SBF high dose treatment group, indicating that PP-1 activity increased, further indicating that SBF could increase the expression level of PP-1. And the results showed that SBF could reverse the increase of Tau protein phosphorylation level induced by $\mathrm{A} \beta_{25-35}$ in $\mathrm{N} 2 \mathrm{a}$ cells.

\section{CONCLUSiON}

This study suggests that the increase of Tau protein phosphorylation in N2A cells induced by SBF reversal $A \beta_{25-35}$ is achieved by regulating the activity of PP-1. When the activity of PP- 1 was enhanced, it could remove more phosphate, which decrease the hyperphosphorylation level of Tau protein. One of the main pathological features of $\mathrm{AD}$ is the hyperphosphorylation of Tau protein. This study suggests that SBF can reduce the hyperphosphorylation of Tau protein in the brain of AD patients. Whether SBF can protect $\mathrm{AD}$ through other mechanisms needs to be further studied.

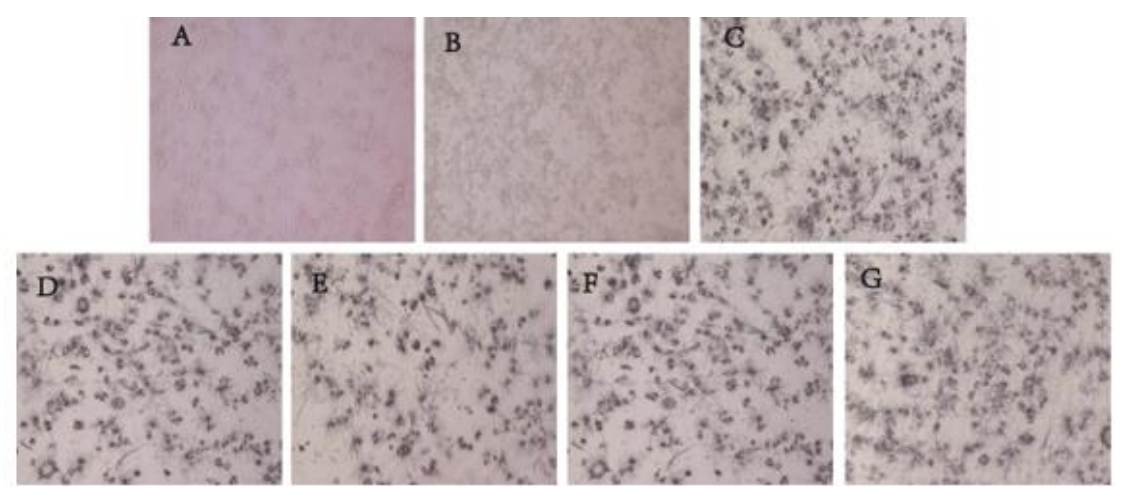

Fig1. The effect of SBF on morphological damage of $N 2$ a cells induced by $A \beta_{25-35}$. A: control group. B: model group. C: OA group. D: A $\beta_{25-35}+O A$ group. $E$ : $S B F(1.125 \mathrm{mg} / L)+A \beta_{25-35}+O A$ group. $F$ : $S B F(2.25 \mathrm{mg} / L)+A \beta_{25-}$ ${ }_{35}+$ OA group. $G$ : $S B F(4.5 m g / L)+A \beta_{25-35}+O A$ group.

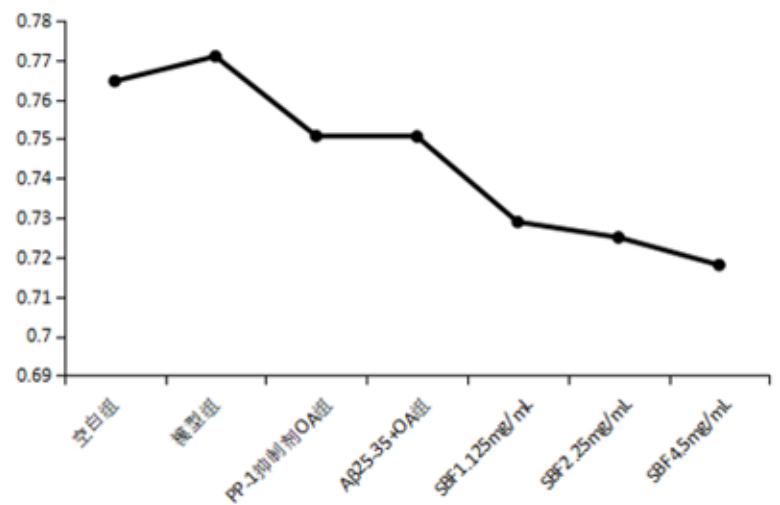

Fig2. The effect of $S B F$ on the release of $L D H$ from $N 2$ a cells induced by $A \beta_{25-35}$

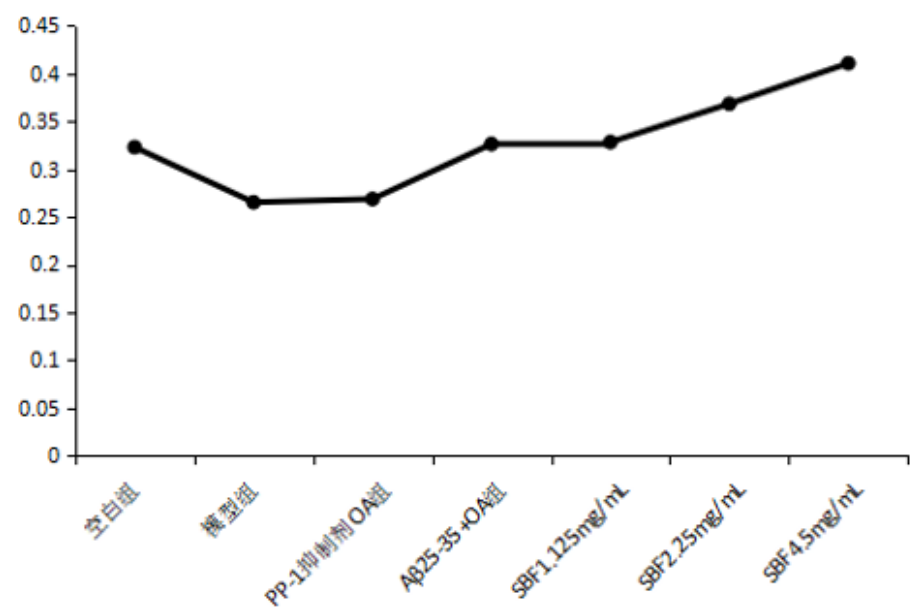

Fig3. The effect of SBF on the survival rate of $N 2$ a cells induced by $A \beta_{25-35}$ 


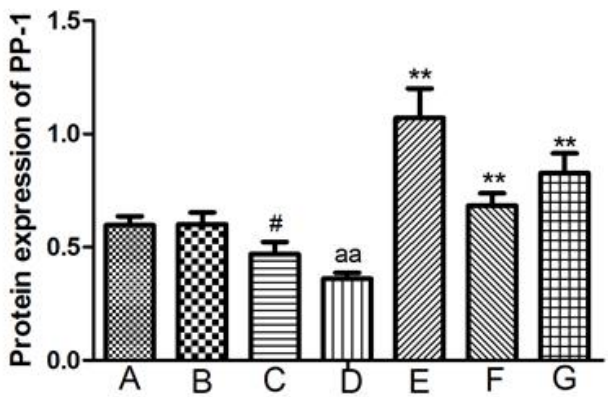

Fig4. The effect of SBF on the protein expression of PP-1 in the N2a cell by composited A $\beta_{25-35 .}$ A: control group. B: model group. $C$ : PP-1 inhibitor OA group. D: $A \beta_{25-35}+O A$ group. $E: S B F(1.125 \mathrm{mg} / L)+A \beta_{25-35}+O A$ group. F: $S B F(2.25 \mathrm{mg} / L)+A \beta_{25-35}+O A$ group. $G: S B F(4.5 \mathrm{mg} / L)+A \beta_{25-35}+O A$ group. Mean $\pm S D . n=3 .{ }^{\#} p<0.05$ vs control group. ${ }^{a a} p<0.01$ vs model group. ${ }^{* *} p<0.01$ vs $A \beta_{25-35}+$ OA group.
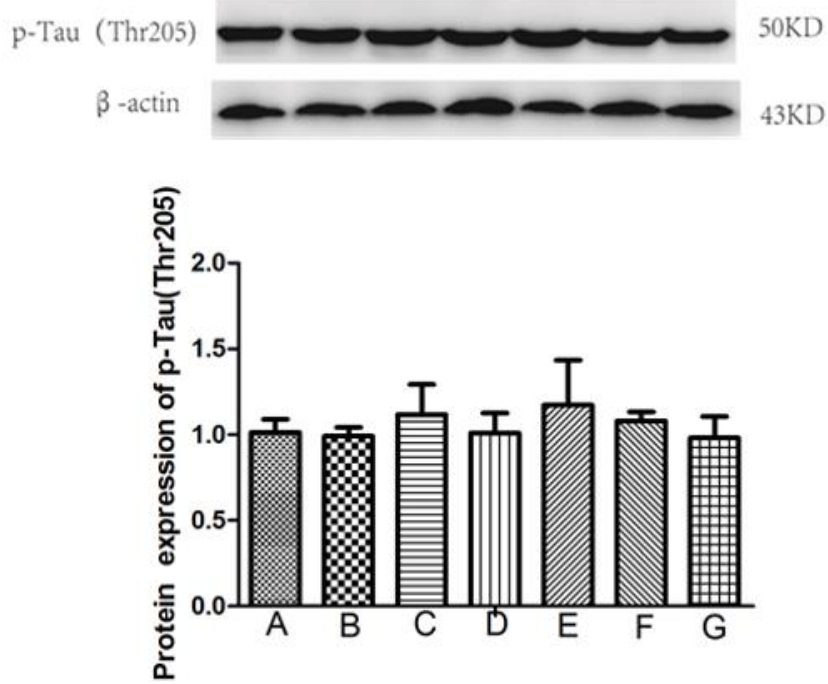

Fig5. The effect of SBF on the protein expression of p-Tau (Thr205) in the N2a cell by composited. A: control group. B: model group. C: PP-1 inhibitor OA group. D: A $\beta_{25-35}+O A$ group. E: $S B F(1.125 \mathrm{mg} / L)+A \beta_{25-35}+O A$ group. F: $S B F(2.25 \mathrm{mg} / L)+A \beta_{25-35}+O A$ group. $G$ : $S B F(4.5 \mathrm{mg} / L)+A \beta_{25-35}+O A$ group. Mean $\pm S D$.

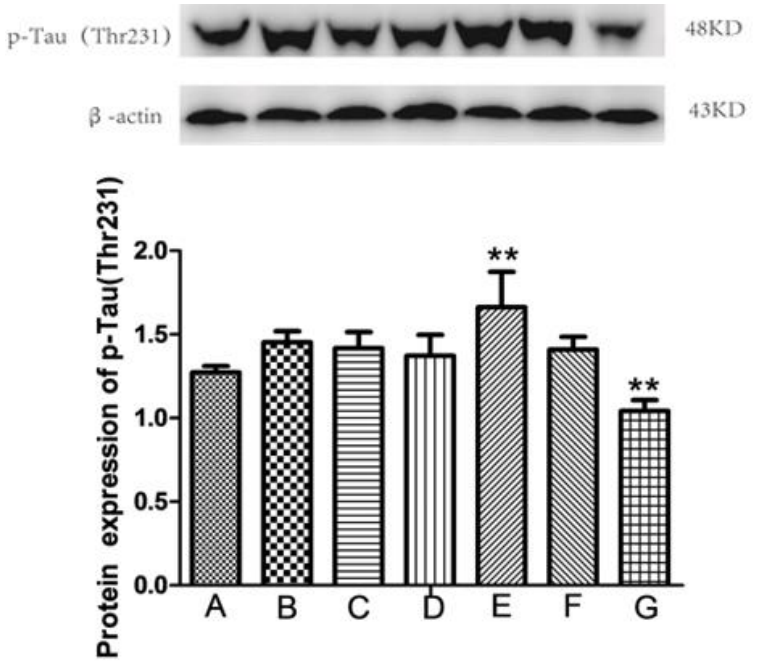

Fig6. The effect of SBF on the protein expression of p-Tau (Thr231) in the N2a cell by composited. A: control group. B: model group. C: PP-1 inhibitor OA group. D: A $\beta_{25-35}+O A$ group. E: $S B F(1.125 \mathrm{mg} / L)+A \beta_{25-35}+O A$ group. F: $S B F(2.25 \mathrm{mg} / L)+A \beta_{25-35}+O A$ group. $G$ : $S B F(4.5 \mathrm{mg} / L)+A \beta_{25-35}+O A$ group. Mean $\pm S D . n=2$. ${ }^{* *} p<0$. 01 vs $A \beta_{25-35}+O A$ group. 

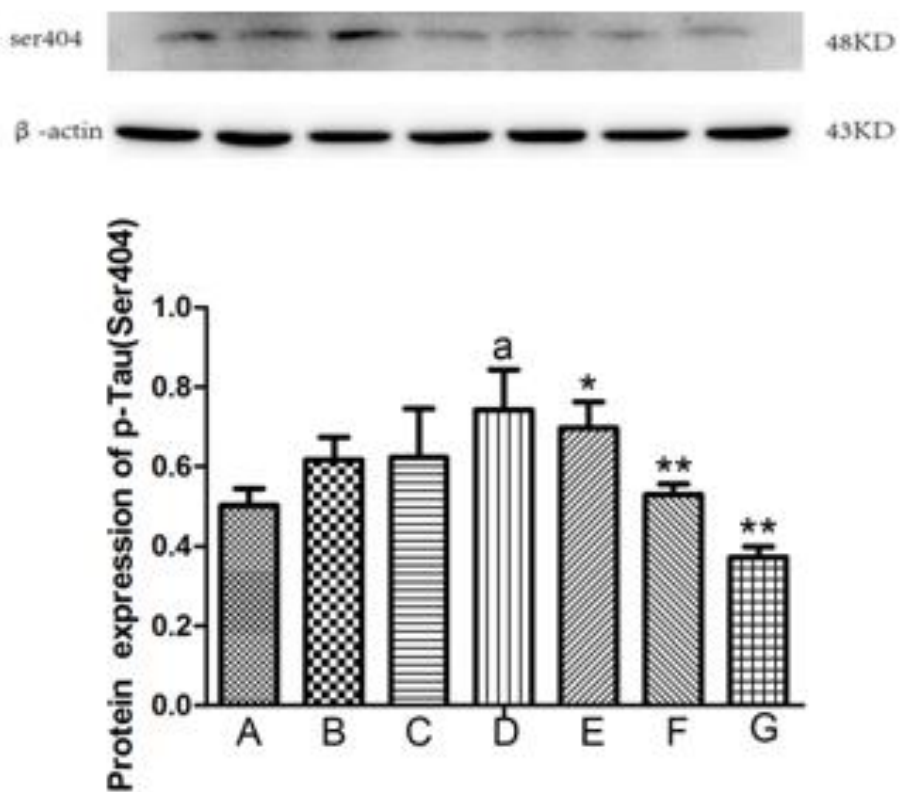

Fig7. The effect of SBF on the protein expression of p-Tau (Ser404) in the N2a cell by composited. A: control group. B: model group. C: PP-1 inhibitor OA group. D: $A \beta_{25-35}+O A$ group. E: $S B F(1.125 \mathrm{mg} / L)+A \beta_{25-35}+O A$ group. F: $S B F(2.25 \mathrm{mg} / L)+A \beta_{25-35}+O A$ group. $G$ : $S B F(4.5 \mathrm{mg} / L)+A \beta_{25-35}+O A$ group. Mean $\pm S D . n=2 .{ }^{a} p<0.05$ vs model group. ${ }^{*} p<0.05$ vs $A \beta_{25-35}+$ OA group, ${ }^{* *} p<0.01$ vs $A \beta_{25-35}+$ OA group.

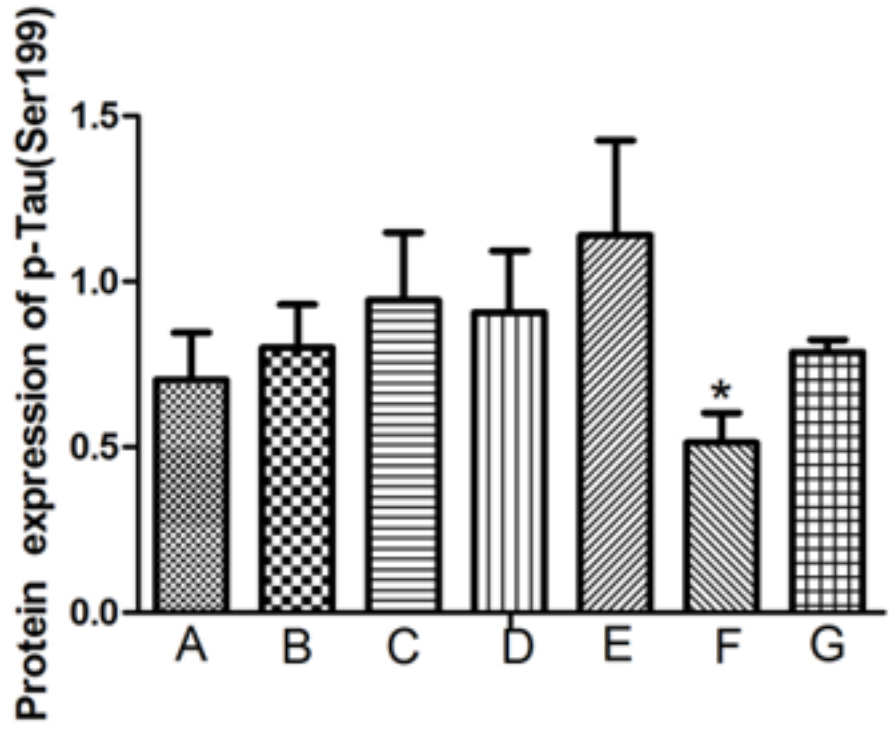

Fig8. The effect of SBF on the protein expression of p-Tau (Ser199) in the N2a cell by composited. A: control group. B: model group. $C$ : PP-1 inhibitor OA group. D: A $\beta_{25-35}+O A$ group. E: $S B F(1.125 \mathrm{mg} / L)+A \beta_{25-35}+O A$ group. F: $S B F(2.25 \mathrm{mg} / L)+A \beta_{25-35}+$ OA group. $G$ : $S B F(4.5 \mathrm{mg} / L)+A \beta_{25-35}+$ OA group. Mean $\pm S D . n=1 .{ }^{*} p<0.05$ vs $A \beta_{25-35}+O A$ group.

\section{REFERENCES}

[1] Bermejo-Pareja F, Llamas-Velasco S, Villarejo-Galende A. Alzheimer's disease prevention: A way forward [J]. Rev Clin Esp, 2016, 216(9): 495-503.

[2] Jicha G A, Berenfeld B, Davies P. Sequence requirements for formation of conformational variants of tau similar to those found in Alzheimer's disease [J]. J Neurosci Res, 2015, 55(6): 713-723.

[3] Silva E F D C E, Henriques A G, Ana Paula Vintém. PP1 Inhibition by A $\beta$ peptide and aluminum as a potential pathological mechanism in Alzheimer's disease [J]. Neurotoxicol Teratol, 2009, 31(2): 85-88.

[4] Flaherty D B, Soria J P, Tomasiewicz H G, et al. Phosphorylation of human tau protein by microtubuleassociated kinases: GSK3- $\beta$ and CDK5 are key participants [J]. J Neurosci Res, 2015, 62(3): 463-472.

[5] Irshad S, Gillett C, Pinder S E, et al. Assessment of microtubule-associated protein (MAP)-Tau expression as a predictive and prognostic marker in TACT; a trial assessing substitution of sequential docetaxel for FEC as adjuvant chemotherapy for early breast cancer [J]. Breast Cancer Res Treat, 2014, 144(2): 331-341. 
[6] Sayas C L, Tortosa E, Bollati F, et al. Tau regulates the localization and function of End-binding proteins 1 and 3 in developing neuronal cells [J]. J Neurochem, 2015, 133(5): 653-667.

[7] Peng Xiaosong, Chen Xiaochun, Huang Junshan, et al. Abnormal phosphorylation of tau protein in rat hippocampal neurons induced by $A \beta_{25-35}$ injection [J]. Chinese Journal of Neurology, 2004, 37 (6): 533-537.

[8] Lopresti P. Inducible expression of a truncated form of Tau in oligodendrocytes elicits gait abnormalities and a decrease in myelin: implications for selective CNS degenerative diseases [J]. Neurochem Res, 2015, 40(11): 2188-2199.

[9] Kong Xiangyi, Shi Kai, Zhao Qing. Research progress of blood markers in Alzheimer's disease [J]. Chinese Journal of Gerontology, 2016, 36(5): 1260-1263.

[10] Sun Lingzhi, Ruan Zhigang, Liu Jing, et al. Research progress of A $\beta$ and tau protein from independence theory to union theory on Alzheimer's Disease [J]. Journal of Neuroanatomy, 2012, 28(4): 419-422.

[11] Guo Ke, Miao Hong, Wang Shusong, et al. The inhibitory effect of flavonoids on NFT deposition and the regulatory mechanism in rat cortical cells induced by compound $\mathrm{A} \beta[\mathrm{J}]$. Chinese Journal of Pathophysiology, 2016, 32(12): 2147-2156.

[12] Wang Xiaoqing, Gao Yang, Dong Yongcai, et al. Flavonoids from stems and leaves of Scutellaria baicalensis Georgi inhibit the abnormal production of PHF and the regulatory mechanism of protein phosphatase in rat brain induced by Okadan acid [J]. Chinese Journal of Pathophysiology, 2018, 34(1): 94-100.

[13] Metin D, Gezen-Ak D, Dursun E, et al. Okadaic acid-induced tau hyperphosphorylation and the downregulation of Pin1 expression in primary cortical neurons [J]. J Chem Neuroanat, 2018, 92: 41-47.

Citation: Shang Yazhen, et.al., (2019). Effect of SBF on AB25-35 Induced-Abnormal Changes of PP-1 and Tau Protein Phosphorylation in N2a Cells. International Journal of Medicinal Plants and Natural Products (IJMPNP), 5(2), pp.37-46. http://dx.doi.org/10.20431/2454-7999.0502005

Copyright: (C) 2019 Authors, This is an open-access article distributed under the terms of the Creative Commons Attribution License, which permits unrestricted use, distribution, and reproduction in any medium, provided the original author and source are credited. 